\title{
Ensino de História e Cultura Afro-Brasileira e Africana - o papel da Extensão Universitária na formação continuada de professores em interface com a implementação da Lei Federal no 10.639/2003: por uma Educação Antirracista
}

\author{
Afro-Brazilian and African History and Culture Teaching - the role of University Extension \\ in the continuous teacher training in interface with the implementation of the Federal Law \\ 10.639/2003: for an Anti-racist Education
}

L'Enseignement de l'Histoire et la culture afro-brésilienne et africaine - le rôle de l'Extension Universitaire dans la formation continue des enseignants en interface avec la mise en cuvre de la loi fédérale 10.639/2003: pour une Education Antiraciste

Viviane Adriana Saballa ${ }^{1}$ Universidade Federal de Pelotas

Resumo: O artigo oferta um panorama de políticas educacionais que estabelecem relação direta com a temática da promoção da igualdade racial e de combate ao racismo, discriminação e injustiças. Buscamos evidenciar o papel da extensão universitária, por meio de um apanhado histórico, destacando seu compromisso social, de modo a proporcionar reflexões de cunho antirracista na educação. Estabelecemos ligação entre extensão universitária e formação continuada através da apresentação do curso em EaD Procedimentos Didático-Pedagógicos Aplicáveis em História e Cultura Afro-Brasileira, vinculado ao Departamento de Educação e Desenvolvimento Social (DEDS) da Pró-Reitoria de Extensão da Universidade Federal do Rio Grande do Sul (UFRGS), evidenciando sua forma precursora na aplicabilidade da Lei n ${ }^{\circ}$ 10.639/2003.

Palavras-chave: Lei 10.639/2003. Políticas Educacionais. Extensão Universitária. Formação Continuada. Educação Antirracista.

Abstract: The Article deals with an overview concerning educational policies which set a direct relation with the issue of the promotion of racial equality and the combat against racism, prejudice and injustices. We sought to highlight the role of the University Extension, through a historical description, highlighting its social commitment, providing considerations of anti-racist mark in Education. We make connections between University Extension and continuous training, through the presentation of the Distance Learning course Educational and Teaching Procedures Applicable in Afro-Brazilian History and Culture, linked to the Education and Social Development Department (DEDS) of the Dean of Extension of the Federal University of Rio Grande do Sul (UFRGS), highlighting its pioneering feature in the applicability fo the Law 10. 639/2003.

Keywords: Law 10.639/2003. Educational Policies. University Extension. Continuous Training. Anti-racist Education.

\footnotetext{
${ }^{1}$ Doutora em História pela Universidade Federal do Rio Grande do Sul/UFRGS. Professora na Universidade Federal de Pelotas/UFPel, Instituto de Ciências Humanas/ICH, Dep. de História. E-mail: vivianesaballa@gmail.com. Lattes: http://lattes.cnpq.br/0171453451447998. ORCID: https://orcid.org/o0000002-0653-7293.
} 
Résumé: L’Article offre un aperçu des politiques éducatives qui établissent une relation directe avec le thème de la promotion de l'égalité raciale et lutte contre le racisme, la discrimination et l'injustice. Nous cherchons à mettre en évidence le rôle de la vulgarisation universitaire, à travers d'un aperçu historique, valoriser son engagement social, apporter des réflexions de nature antiraciste dans l'éducation. Nous avons établi un lien entre University Extension et la formation continue, à travers de la présentation du cours d'enseignement à distance Procédures didactiques et pédagogiques applicables à l'histoire et à la culture afro-brésilienne, lié au Ministère de Education de l'Université Fédérale de Rio Grande do Sul (UFRGS), montrant sa forme de précurseur dans l'applicabilité de la loi 10.639/2003.

Mots-clés: Loi 10.639/2003. Politiques éducatives. Extension Universitaire. Formation continue. Éducation antiraciste.

Recebido em: 19 de junho de 2020

Aceito em: 16 de julho de 2020

\section{Introduzindo abordagens da Educação das Relações Étnico-Raciais}

Em nosso país, pensar a abordagem da Educação das Relações Étnico-Raciais requer levar em conta o cenário do final dos anos 1990, quando - sob muitos aspectos politicamente se consolidam muitas das lutas do Movimento Negro contra o racismo e a desigualdade racial. É consenso pensar que, principalmente na segunda metade dessa década, multiplicaram-se programas de combate à discriminação racial, inclusive com financiamento do governo federal (ANDRADE; FREITAS; BARBOSA, 201 1, p. 1). Em tempo, cabe referir a importância dos Parâmetros Curriculares Nacionais (PCNs, 1998), quando trouxeram à cena o debate referente à pluralidade cultural, um relevante deslocamento em direção à “sensibilização intercultural docente” (CANEN, 2001, p. 212).

No ano de 2003, é sancionada a Lei $n^{\circ} 10.639$, alterando a Lei $n^{\circ} 9.394 / 1996$, que estabelece as diretrizes e bases da educação nacional (LDB). Com a inclusão dos artigos 26-A e 79-A, o ensino sobre História e Cultura Afro-Brasileira se torna obrigatório nos estabelecimentos da educação básica, oficiais e particulares:

§ 1o O conteúdo programático a que se refere o caput deste artigo [Art. 26A \ incluirá o estudo da História da África e dos Africanos, a luta dos negros no Brasil, a cultura negra brasileira e o negro na formação da sociedade nacional, resgatando a contribuição do povo negro nas áreas social, econômica e política pertinentes à História do Brasil (BRASIL, 2003).

O documento ainda afirma que os conteúdos referentes à História e Cultura AfroBrasileira devem ser ministrados em todo o currículo escolar. A partir disso, temos uma 
Revista Educação e Políticas em Debate - v. 9, n. 3, p. 692 - 707, set/dez. 2020 - ISSN 2238-8346 segunda onda de movimento pela Educação das Relações Étnico-Raciais, quando ocorre "uma série de iniciativas no âmbito acadêmico, dos movimentos sociais, das ONGs e, principalmente, de órgãos governamentais federais com vistas a sua implementação nos sistemas de ensino federal, estaduais e municipais” (OLIVEIRA, 2008, p. 7). Com a promulgação da Lei, como forma de "garantir" seu cumprimento no sistema educacional brasileiro, houve importantes iniciativas, como a criação da Secretaria de Educação Continuada, Alfabetização e Diversidade (SECAD) e a publicação, pelo MEC, no ano de 2004, das Diretrizes Curriculares Nacionais para a Educação das Relações Étnico-Raciais e para o Ensino de História e Cultura AfroBrasileira e Africana. Assim, finalmente, a legislação adentra as escolas.

As DCNs instituídas pela Resolução $n^{0}$ 1/2004, ${ }^{2}$ do Conselho Nacional de Educação (CNE)/Conselho Pleno (CP), estabeleceram um marco, na medida em que regularam as prerrogativas do trato das questões e das temáticas que dizem respeito aos afrodescendentes, sua História e suas contribuições para a formação da sociedade brasileira. Sua fundamentação reside no Parecer CNE no 3/2004, que deu impulso, entre outros pressupostos, ao fomento de programas de formação inicial e continuada de professores.

O documento solicita estratégias e modos para a transposição da inclusão étnico-racial, destacando inúmeras providências para tal, dentre as quais citamos: a) Registro da história não contada dos negros brasileiros; b) Apoio sistemático aos professores para elaboração de planos, projetos, seleção de conteúdos e métodos de ensino, cujo foco seja História e Cultura AfroBrasileira e Africana e a Educação das Relações Étnico-Raciais; c) Mapeamento e divulgação de experiências pedagógicas de escolas, estabelecimentos de ensino superior, secretarias de educação; d) Articulação entre os sistemas de ensino, estabelecimentos de ensino superior, centros de pesquisa, Núcleos de Estudos Afro-Brasileiros, escolas, comunidade e movimentos sociais, visando à preparação de professores para a diversidade étnico-racial; e) Inclusão de discussão da questão racial como parte integrante da matriz curricular, tanto dos cursos de Licenciatura para educação infantil, anos iniciais e finais da Educação Fundamental, educação média, Educação de Jovens e Adultos, como de processos de formação continuada de professores, inclusive de docentes no ensino superior; f) Edição de livros e de materiais didáticos, para diferentes níveis e modalidades de ensino; entre outras.

Frente ao exposto, este texto visa evidenciar o papel da extensão universitária e a importância da formação continuada de professores, bem como apresentar experiência pioneira de ação extensionista do Departamento de Educação e Desenvolvimento Social (DEDS), vinculado à Pró-Reitoria de Extensão (PROREXT) da Universidade Federal do

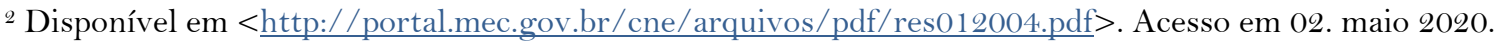


Revista Educação e Políticas em Debate - v. 9, n. 3, p. 692 - 707, set/dez. 2020 - ISSN 2238-8346

Rio Grande do Sul (UFRGS). A experiência a ser relatada estabeleceu - com êxito correlação direta com as Diretrizes Curriculares Nacionais para a Educação das Relações Étnico-Raciais e para o Ensino de História e Cultura Africana e Afro-Brasileira, na formação continuada de professores, em atendimento à Lei $\mathrm{n}^{\circ} 10.639 / 2003,^{3}$ que busca o reconhecimento da diversidade sociocultural no contexto das políticas educacionais de combate ao racismo e à discriminação, contribuindo para a superação de injustiças, em detrimento a posições discriminatórias ou excludentes.

\section{Extensão universitária e a importância da formação continuada de professores}

No ensino superior, o tripé ensino, pesquisa e extensão visa estabelecer ações para pensar o Brasil via produção e divulgação de conhecimentos científicos, culturais e artísticos. Especificamente sobre a extensão, o intuito consiste em cooperar para notabilizar a intervenção de professores e comunidade escolar que atuam no ensino público (FARIA FILHO; BAHIENSE, 2004, p. 16).

Sob a perspectiva histórica, a extensão universitária brasileira se faz presente nas normas governamentais ainda na década de 1960, apresentando modos de impulsionar a conexão entre a comunidade e as universidades (NAVES, 2008, p. 16). Seu surgimento estaria vinculado à forte influência de distintos posicionamentos e vertentes: o modelo de extensão norte-americano e as universidades populares, ambos tomavam por base uma visão assistencialista (GURGEL, 1986). Tal percepção sofreu alterações ao longo de nossa História. A década de 1980 foi representativa, pois novas direções foram pleiteadas, o que circunscreveu a necessidade de uma nova forma de compreender a relação entre Universidade e comunidade. A ideia de assistencialismo é abandonada, devido à compreensão de que a Universidade "corria o risco de substituir ações sociais que seriam, na realidade, da alçada dos governos" (NAVES, 2008, p. 16). Neste momento, prevalece uma concepção que estabelece a função social e acadêmica da extensão universitária, a qual é reafirmada pelo FORPROEX, ${ }^{4}$ ao salientar o compromisso social da Universidade como objetivo principal da extensão. O que podemos denotar é a extensão universitária no esforço de atenção à sociedade, empenhando-se em conhecê-la, em auscultar as preocupações que

\footnotetext{
${ }^{3}$ Altera a Lei no 9.394, de 20 de dezembro de 1996, que estabelece as diretrizes e bases da educação nacional, para incluir no currículo oficial da rede de ensino a obrigatoriedade da temática "História e Cultura Afro-Brasileira". Disponível em <http://www.planalto.gov.br/ccivil_03/leis/2003/L10.639.htm>. Acesso em 26 jan. 2012. 4. FORPROEX: Fórum Nacional de Pró-Reitores de Extensão Universitária das Universidades Públicas Brasileiras. Sua constituição foi de suma importância, pois através dela a extensão universitária passou a ser considerada, também, a partir de uma concepção acadêmica (NAVES, 2008, p. 17).
} 
Revista Educação e Políticas em Debate - v. 9, n. 3, p. 692 - 707, set/dez. 2020 - ISSN 2238-8346 esta produz, "bem como em valorizar o contexto em que as atividades se inserem, na busca de relação de reciprocidade, mutuamente transformadora [ …]” (NAVES, 2008, p. 17).

Nesse sentido, "a universidade, enquanto sujeito, assume sua interconexão com a sociedade, o que significa [...] admitir sua responsabilidade como agente capaz de reconhecer seu significado na interlocução entre os distintos saberes” (PIZZI; BASTOS, 2016, p. 4). Assim, a preocupação com a formação dos professores ocupa papel central nesse novo ativismo assumido pela extensão universitária, marcando "o discurso e a agenda das políticas educativas dos últimos decênios, pelo menos nos países ditos desenvolvidos" (ESTRELA, 2006, p. 43). A formação continuada passa, então, a ser vista como um espaço favorável ao processo de profissionalização e da constituição da identidade docente. Pelas novas DCNs, ela abrange sentidos coletivos, profissionais e organizacionais, assim como a própria reconsideração da configuração do processo pedagógico, valores e saberes. Ainda:

Envolve atividades de extensão, grupos de estudos, reuniões pedagógicas, cursos, programas e ações para além da formação mínima exigida ao exercício do magistério na educação básica, tendo como principal finalidade a reflexão sobre a prática educacional e a busca de aperfeiçoamento técnico, pedagógico, ético e político do profissional docente (DOURADO, 2015, p. 14).

A formação continuada deve agregar novos saberes e práticas, articuladas às políticas e à gestão da educação, à área de atuação do profissional e às instituições de educação básica, em suas diferentes etapas e modalidades (DOURADO, 2015, p. 309).

As novas DCNs, em consonância com a legislação, definem que a formação continuada envolve: I. Atividades formativas organizadas pelos sistemas, redes e instituições de educação básica, incluindo desenvolvimento de projetos, inovações pedagógicas, entre outros; II. Atividades e/ou cursos de atualização, com carga horária mínima de 20 (vinte) horas e máxima de 80 (oitenta) horas, por atividades formativas diversas, direcionadas à melhoria do exercício do docente; III. Atividades e/ou cursos de extensão, oferecidas por atividades formativas diversas, em consonância com o projeto de extensão aprovado pela instituição de educação superior formadora; IV. Cursos de aperfeiçoamento, com carga horária mínima de 180 (cento e oitenta) horas, por atividades formativas diversas, em consonância com o projeto pedagógico da instituição de educação superior; V. cursos de especialização lato sensu por atividades formativas diversas, em consonância com o projeto pedagógico da instituição de educação superior e de acordo com as normas e resoluções do CNE; VI. Cursos ou programas de mestrado acadêmico ou profissional, por atividades formativas diversas, de acordo com o projeto pedagógico do curso/programa da instituição de educação superior, respeitadas as normas e resoluções do CNE e da Coordenação de Aperfeiçoamento de Pessoal de Nível 
Revista Educação e Políticas em Debate - v. 9, n. 3, p. 692 - 707, set/dez. 2020 - ISSN 2238-8346

Superior (Capes); VII. Cursos ou programas de doutorado, por atividades formativas diversas, de acordo com o projeto pedagógico do curso/programa da instituição de educação superior, respeitadas as normas e resoluções do CNE e da Capes.

\section{Procedimentos Didático-Pedagógicos Aplicáveis em História e Cultura Afro- Brasileira: colaboração para a aplicabilidade da Lei $n^{\circ}$ 10.639/2003}

A LDB - Lei nº 9.394/96 -, em seu artigo 67, afirma que os sistemas de ensino devem promover a valorização dos profissionais (NEZ, 2014, p. 112), assegurando-lhes “aperfeiçoamento profissional continuado” (BRASIL, 1996, p. 68). Com vistas a atender a essas prerrogativas, buscando formas de efetivar a adoção de políticas públicas educacionais e de estratégias pedagógicas para a valorização da História e da Cultura Africana e Afro-Brasileira, desenvolver reflexões sobre a diversidade sociocultural e propor mecanismos institucionais para a superação da desigualdade étnico-racial na educação brasileira, desde a entrada em vigor da Lei $n^{\circ}$ 10.639/2003, profissionais do Departamento de Educação e Desenvolvimento Social criaram o Programa de Educação Antirracista no Cotidiano Escolar e Acadêmico.

O Programa tem como foco desenvolver projetos voltados à formação pedagógica dos educadores do Estado do Rio Grande do Sul sobre as temáticas das relações raciais. Para tanto, estabelece parcerias com as secretarias municipais de educação (SMEDs) da região metropolitana de Porto Alegre, elo fundamental do contato entre profissionais do ensino básico e comunidade acadêmica. As ações desenvolvidas nesse Programa são de tamanha expressão que equivalem a um Núcleo de Estudos Afro-Brasileiros (Neab) dentro da UFRGS. Assim, seu percurso é conduzido privilegiando um histórico extensionista de formação continuada de educadores, preocupado com o ensino e a pesquisa da História e Cultura AfroBrasileira e Africana, no sentido de efetivação da Lei nº 10.639/2003.

No ano de 2009, o Programa participou do Edital UNIAFRO/MEC - Programa de Ações Afirmativas para a População Negra nas Instituições Federais e Estaduais de Ensino Superior. E foi via aprovação deste edital que pôde realizar o curso Procedimentos DidáticoPedagógicos Aplicáveis em História e Cultura Afro-Brasileira. ${ }^{5}$ Esse feito foi representativo, pois através desse curso o Programa reafirmou e efetivou o seu lugar de formador de educadores da educação básica, no que tange à temática da diversidade.

\footnotetext{
${ }^{5}$ As informações apresentadas aqui sobre o curso são baseadas na obra Procedimentos Didático-Pedagógicos Aplicáveis em História e Cultura Afro-Brasileira (SABALLA, Viviane A.; BITTENCOURT JÚNIOR, Iosvaldyr C. Procedimentos Didático-Pedagógicos Aplicáveis em História e Cultura Afro-Brasileira. Porto Alegre, Editora da UFRGS, 2012).
} 
Revista Educação e Políticas em Debate - v. 9, n. 3, p. 692 - 707, set/dez. 2020 - ISSN 2238-8346

O curso Procedimentos Didático-Pedagógicos Aplicáveis em História e Cultura Afro-Brasileira foi inovador. Configurou-se como uma ação de extensão a distância ofertada, por oito meses, a um público de 500 professores das redes municipais de ensino de Porto Alegre e região metropolitana (envolvendo 150 escolas) ${ }^{6}$, instituições da sociedade civil e integrantes do Movimento Negro. Entre seus objetivos, propôs habilitar educadores no cumprimento da Lei $\mathrm{n}^{\circ} 10.639 / 2003$, fortalecer parcerias e estimular fóruns de discussão sobre a temática da Educação das Relações Étnico-Raciais no ambiente escolar. Os cursistas, predominantemente, estavam atuantes em sala de aula. Receberam o certificado de curso de extensão da UFRGS, com carga horária de 200h, 264 educadores.

Cabe aqui destacar o diferencial de ter sido ofertado em EaD:

Modalidade de ensino que se diferencia por permitir que o aluno não esteja fisicamente presente em um ambiente formal de ensino-aprendizagem, assim como oportunizando que ele faça seu autoestudo (CUSTÓDIO; MONNI, 2012, p. 140).

Assim, o curso esteve diante de um duplo desafio: trabalhar para a inserção da temática e favorecer/promover intimidade com os recursos tecnológicos. Nessa perspectiva, o sistema tutorial acaba sendo:

Um conjunto de ações pedagógicas que contribuem para desenvolver e potencializar as capacidades básicas dos alunos, orientando-os a obterem crescimento e autonomia, intelectual e política (SOUZA, 2004, p. 5).

O DEDS, por meio desse curso, gerou formação continuada de professores municipais e estaduais de ensino, produziu material didático e fomentou o diálogo com a sociedade, reforçando o compromisso interinstitucional com as políticas de promoção social, articulando diversas redes de apoio e ações conjuntas. Essas, por sua vez, geraram processos que desvelaram questões raciais e a busca do antirracismo na educação brasileira, estreitando alianças possíveis entre escolas e a Universidade, "na medida em que o pensamento crítico antirracista é forjado nesses dois lugares de produção de conhecimento” (OLIVEIRA, 2020, p. 16).

A grande dificuldade que acaba se impondo é pretender a superação do racismo, manifesto nas mais variadas esferas, como doutrinárias-ideológicas, atitudinais, de preferências e sistema social, em uma sociedade que não se reconhece como racista. Transpor os muros construídos pela nossa suposta democracia racial na História do Brasil é tarefa laboriosa de ser executada, ainda mais diante de sucessivas reelaborações promovidas:

O mito da democracia racial [...] parece ter perdido terreno como recurso de legitimação simbólica à disposição das elites brasileiras. Cooptação, repressão

\footnotetext{
${ }^{6}$ Envolveu educadores das redes de ensino situadas nos municípios de Novo Hamburgo, Alvorada, Cachoeirinha, Esteio, Gramado, Porto Alegre, São Leopoldo e Sapucaia do Sul.
} 
Revista Educação e Políticas em Debate - v. 9, n. 3, p. 692 - 707, set/dez. 2020 - ISSN 2238-8346

e políticas distributivas são os mecanismos que o Estado brasileiro pode ativar para lidar com a questão racial no Brasil e é difícil antecipar hoje de que maneira eles serão combinados no futuro (HASENBALG, 1991, p. 187).

São inúmeros os recursos operacionalizados pela base político-ideológica para fomentar e legitimar, cada vez mais, a negação de nossa própria trajetória, enquanto Nação, na busca de inviabilizar uma reparação histórica.

Segundo Guimarães, "o grande problema para combater o racismo, no Brasil, consiste na eminência de sua invisibilidade, posto que é reiteradamente negado e confundido com formas de discriminação de classe” (GUIMARÃES, 2009, p. 226). E, no nosso país, são múltiplos os silenciamentos frente à questão étnico-racial na educação; eles residem em diferentes meios, como em suas políticas e legislações, bem como na implementação prática do que consta nessas Diretrizes:

A elaboração e implementação de políticas públicas educacionais democráticas constituem um caminho para a garantia desse direito, o que pode ser assegurado através de uma legislação e de práticas que tenham como propósito a universalização do acesso ao ensino e da permanência nele, favorecendo processos democráticos de igualdade e solidariedade. No entanto, as políticas educacionais no Brasil são insuficientes no tocante à oferta e garantia de uma educação que divulgue a história da população afro-brasileira, que valorize sua cultura e que afirme a identidade negra (SOUZA; REIS; MENEZES, 2013, p. 10).

Procedimentos Didático-Pedagógicos Aplicáveis em História e Cultura Afro-Brasileira foi um convite à sociedade para o acompanhamento da execução de políticas curriculares que visam à correção de históricas desigualdades e exclusões. A parceria firmada com gestores dos sistemas municipais de ensino e professores criou condições de envolvimento com as relações étnico-raciais no seio social e suas decorrências, como a discriminação e o racismo, motivando a construção de ações voltadas a superá-los, via criação de procedimentos didático-pedagógicos e Ensino da História e Cultura Afro-Brasileira e Africana. O curso e a forma de efetivá-lo denotaram uma escolha política, no sentido de fortalecimento de noções de pertencimento, pois a:

Análise entre espaço e poder revela, sobretudo, uma alienação que preside a desterritorialidade dos negros, manifestada principalmente por um acesso diferenciado aos espaços e por uma invisibilidade latentes nas representações [...] (D’ADESKY, 2009, p. 125).

Como nas escolas, onde percebemos uma ruptura étnica, quando os negros são ignorados em seus diferenciados espaços de ensino, por falta de representatividade na biblioteca, em corredores e murais, por exemplo, do mesmo modo que nos conteúdos trabalhados em sala de aula, em diferentes campos do saber. 
Revista Educação e Políticas em Debate - v. 9, n. 3, p. 692 - 707, set/dez. 2020 - ISSN 2238-8346

Ressaltamos, através dessa extensão, o quanto a formação continuada vem assumindo crucial papel no que tange à busca de uma educação e um ensino de qualidade em nosso país, que considerem os sujeitos históricos em sua diversidade, bem como a inclusão da temática afro-brasileira na estrutura curricular de todos os níveis e modalidades de ensino na educação básica, que se dá de modo tímido e insatisfatório em sua plenitude. Aos próprios cursos universitários de Licenciatura falta clareza de como tratar pedagogicamente as questões de Educação das Relações Étnico-Raciais e de Ensino de História e Cultura Afro-brasileira. Ainda prepondera a mentalidade de que é necessária apenas uma disciplina que dê conta da Lei, ignorando que o tema deve ser um elemento estruturante do currículo.

Diante disso, cabe às universidades propor novos paradigmas para uma educação centrada na diversidade étnico-racial, tomando por apoio, entre outras, Leis como a $\mathrm{n}^{\circ}$ 10.639/2003 e a n ${ }^{0} 11.645 / 200$, somadas às DCNs (Brasil, 2005). O papel da educação como base transformadora da sociedade deve ser otimizado.

Nesse contexto, o curso Procedimentos Didático-Pedagógicos Aplicáveis em História e Cultura Afro-Brasileira se propôs à criação de novos paradigmas curriculares em educação, na forma como foi pensando pelos seus idealizadores (Equipe de Coordenação e Planejamento, tendo como integrantes parceiros das SMEDs e UFRGS). Envolveu a responsabilização político-pedagógica das administrações das redes de ensino e das gestões escolares, destacando a força do trabalho coletivo, que envolveu também as coordenações do curso da UFRGS, das redes e dos coordenadores e tutores. Tomando como base o tripé ensino, pesquisa e extensão, discutiu a formação de professores e de outros profissionais atuantes nas redes de ensino, comprometidos com a obrigatoriedade e inclusão da temática História Africana e Afro-Brasileira no currículo escolar da educação básica.

O curso foi organizado em seis módulos, com articulação direta entre si, envolvendo: 1) Uso de tecnologia; 2) Diversidade e Direitos Humanos; 3) Atos legais e atos normativos; 4) A temática na estrutura e no funcionamento da escola; 5) A temática na sala de aula e nos demais tempos e espaços escolares e; 6) Avaliação na temática. Refletindo sobre o papel da extensão na formação continuada de professores em atendimento à Lei $\mathrm{n}^{\circ} 10.639 / 2003$, cabem algumas considerações advindas dessa experiência ofertada aos professores do ensino básico. Para apresentá-las de uma forma didática, selecionamos informações por categorias de envolvidos: corpo docente, coordenações locais e SMEDs, tutoria presencial e a distância e cursistas.

Dentre diferentes abordagens trabalhadas, citamos aqui algumas, por meio das quais os professores ministrantes de módulos na plataforma Moodle oportunizaram diversificadas possibilidades de reflexão sobre diferentes aspectos implicados na Lei $\mathrm{n}^{\circ}$ 10.639/2013, em um convite a "repensar conceitos e adotar procedimentos escolares e didático-pedagógicos 
Revista Educação e Políticas em Debate - v. 9, n. 3, p. 692 - 707, set/dez. 2020 - ISSN 2238-8346 adequados aos propósitos sociais dessa nova legislação" (MACEDO, 2012, p. 32). O currículo oculto foi discutido no curso, cuja:

Visibilidade leva os sujeitos envolvidos no processo de aprendizagem a olhar, ver e reconhecer o múltiplo, o diferente, a diversidade que impregna o entorno cultural da sala de aula e da comunidade escolar, em um sentido mais amplo (MACEDO, 2012, p. 32).

Também se trabalhou o significado do atendimento e da adoção de procedimentos pedagógicos coerentes às ordens da legislação centrada no tema, o que acaba por requerer uma extensa e abrangente reavaliação do currículo escolar, imputando alterações na estrutura e no funcionamento. O curso convidou todos os envolvidos a se comprometerem com a causa em prol da qualificação do projeto pedagógico da escola, tomando como ponto de partida a premissa básica de que "as matrizes culturais afro-brasileiras devam ser estruturantes do currículo escolar, a partir do Projeto Político Pedagógico das instituições escolares [...]” (BITTENCOURT JÚNIOR; SILVA, 2016, p. 226).

Os valores civilizatórios africanos e afro-brasileiros receberam devido tratamento ao serem valorizados como instância cultural de toda a sociedade brasileira. A temática AfroBrasileira como base fundamental do currículo foi discutida no âmbito da avaliação, como forma de reorientação de aprendizagens. Foi dado reconhecimento da importância da Diáspora e da desterritorialização africana, na dimensão de reinvenção de práticas educativas. O objetivo foi, acima de tudo, diagnosticar "as prováveis dificuldades na prática escolar da diversidade cultural e étnico-racial”, propondo "alternativas para a reformulação de procedimentos didático-pedagógicos na temática - condição necessária para que a legislação antirracista produza os efeitos esperados na sociedade" (MACEDO, 2012, p. 34).

Para o bom desenvolvimento do curso Procedimentos Didático-Pedagógicos Aplicáveis em História e Cultura Afro-Brasileira, foi crucial a articulação entre as secretarias municipais, cuja participação foi ativa desde a formulação do projeto submetido ao Edital UNIAFRO. A capacidade de associação entre a rede municipal e a Universidade definiu o êxito na gestão educacional proposta. As representações institucionais assumiram as responsabilidades que abarcam fazer parte de um curso como este, obraram em prol de harmonizar os interesses políticos dos gestores dos sistemas de ensino e de suas diretrizes programáticas, considerando o desafio que é tratar das questões étnico-raciais no âmbito escolar, cientes do:

Conjunto de dificuldades para a implementação de propostas ousadas e desafiadoras, no que concerne ao trato do racismo no cotidiano escolar eà educação antirracista, que inviabilizem o alcance de seus intentos (SILVA, 2012, p. 124). 
Revista Educação e Políticas em Debate - v. 9, n. 3, p. 692 - 707, set/dez. 2020 - ISSN 2238-8346

Salientamos, ainda, que as formas de articulação desenvolvidas potencializaram lideranças no verdadeiro sentido de "gestor com espírito público" (SILVA, 2012, p. 124) e que o priorado básico foi estabelecer relação de “[ [...] respeito com as parcerias, afirmando uma pedagogia crítica” (SILVA, 2012, p. 125).

O esforço desenvolvido pelos tutores a distância operacionalizou toda a logística para que os cursantes chegassem à conclusão dos trabalhos, suprindo:

A deficiência da formação inicial nos cursos de Pedagogia e nas diferentes licenciaturas pela ausência de conteúdos conceituais e orientações sobre procedimentos didático-pedagógicos adequados ao tratamento da temática História e Cultura Africana e Afro-Brasileira (SOUZA; FERNANDES, 2012, p. 129).

Todo o trabalho docente só foi possível, em sua intenção de completude, graças ao suporte dado pelos tutores. Administrar a qualidade e a quantidade de informações, metodologias e programação prevista requereu preparo e comprometimento desses profissionais, que foram igualmente fundamentais para a necessária motivação e conscientização dos cursistas quanto à premente importância do consubstanciamento de constructos de ações positivas nas mudanças educacionais no ensino básico. Os tutores não apenas ofertaram assessoramento/orientações aos cursistas, administraram a plataforma, direcionaram orientações de modos de aplicação de ferramentas tecnológicas, indicaram possibilidades de utilização do material didático, como também se dispuseram a orientar na execução das atividades propostas e avaliação da abrangência dos efeitos do curso nas escolas e comunidades escolares.

Por último, queremos ressaltar as considerações e constatações dos cursistas. A motivação incide pela evidência de noção de comprometimento e entrega desenvolvida por eles ao longo da trajetória experienciada. O primeiro destaque foi a descoberta de novos alcances ofertados de construção de atividades práticas relacionadas à História e Cultura Africana e Afro-Brasileira, com o uso de diferenciados recursos culturais e pedagógicos locais. Os cursistas se sentiram motivados a elaborar seus próprios materiais pedagógicos, à luz dos conhecimentos adquiridos no curso e da percepção de seus entornos. O segundo aspecto por eles mencionado foi o fortalecimento do papel do professor, enquanto educador, na construção de procedimentos didático-pedagógicos, cujo apoio se deu nos valores culturais decorrentes da História Africana e Afro-Brasileira. Exaltaram seus compromissos como agentes sociais de transformação da realidade em que estão envolvidos. Os docentes, nas escolas, cumprem estratégico papel, na medida em que com eles está:

[...] o trabalho político de aprender/educar/transformar, é viver junto/com e a partir deles os desafios permanentes do fazer educativo. 
Revista Educação e Políticas em Debate - v. 9, n. 3, p. 692 - 707, set/dez. 2020 - ISSN 2238-8346

Com os docentes, se aprende o fazer educação na medida em que eles enfrentam as urgências e as incertezas das relações pedagógicas e, nessas, eles produzem um novo conhecimento e a matéria-prima da transformação, que é a perspectiva da mudança e do avanço do pensamento para uma vida bem vivida, para construção de repertórios sociais e culturais transformativos (OLIVEIRA, 2020, p. 18).

\section{Considerações finais para uma educação antirracista}

Neste texto, buscamos, primeiramente e de modo panorâmico, lançar um sobrevoo por algumas políticas educacionais, através de documentos, pareceres e leis que estabelecem relação direta com a temática da promoção da igualdade racial e de combate ao racismo, discriminação e injustiças. Num segundo momento, procuramos evidenciar o papel da extensão universitária, demostrando definições que nos fazem compreender seu protagonismo e importância como componente do tripé ensino, pesquisa e extensão. Proporcionamos breve apanhado histórico, como modo de contextualizar suas influências e compreensões de papéis, que foram alterando ao longo do tempo, até chegar ao compromisso social, que hoje é indissociável a qualquer ação, procurando amalgamar a escrita com reflexões de cunho antirracista na educação.

Também estabelecemos ligação entre extensão universitária e formação continuada, assumindo este posto de elemento central de transformação da realidade. Por último, apresentamos o curso de extensão em EaD Procedimentos Didático-Pedagógicos Aplicáveis em História e Cultura AfroBrasileira, vinculado ao Departamento de Educação e Desenvolvimento Social da Pró-Reitoria de Extensão da Universidade Federal do Rio Grande do Sul, e sua forma precursora na aplicabilidade da Lei $n^{\circ}$ 10.639/2003. Discorremos sobre os eixos orientadores trabalhados pelos professores responsáveis pelos módulos, no intento de ofertar um panorama do curso como um todo, bem como de aproximar o leitor ao que cada integrante experienciou e vivenciou.

Após demonstrar o papel das coordenações locais e das SMEDs, bem como da tutoria presencial e a distância, expusemos breves considerações dos cursistas sobre seus fazeres e mudanças, enquanto educadores, provocadas pela participação no curso. A experiência proporcionada por esse curso extensionista reafirma o desejo, conforme expressa Tardif (2014, p. 55), da "instituição de uma verdadeira parceria entre professores, corpos universitários de formadores e responsáveis pelo sistema educacional," no desenvolvimento de políticas públicas para qualificação da educação básica.

Tal qualificação se faz urgente quando empreendemos nossos olhares para questões da contribuição da comunidade negra para a formação e edificação da sociedade brasileira, no sentido de reconhecimento da diversidade étnico-racial e cultural desses sujeitos sociais e históricos pertencentes à dinâmica histórica da nação. Que sempre possamos buscar 
Revista Educação e Políticas em Debate - v. 9, n. 3, p. 692 - 707, set/dez. 2020 - ISSN 2238-8346 orientações à educação de professores e de outros educadores ao reconhecimento de oportunidades de construção da cidadania, lembrando que:

As pessoas não herdam, geneticamente, ideias de racismo, sentimentos de preconceito e modos de exercitar a discriminação. Elas se tornam racistas, preconceituosas e discriminadoras no convívio social, situação, muitas vezes, fortalecida pela escola (LOPES, 2008, p. 143).

Que o curso aqui apresentado possa constituir um impulso para a construção de uma pedagogia crítica; que possamos "reconstruir posturas, atitudes, questionar e combater preconceitos, desmontar estereótipos” e que nossas atividades pedagógicas, cada vez mais, se apoiem nas africanidades, "em conhecimentos, valores, postura diante da vida, das outras pessoas, do ambiente natural e social, elaborado por africanos, tanto da Diáspora como do Continente" (SILVA, 2012, p. 11).

De todo o exposto, que fique a certeza do compromisso da Universidade como centro potencializador e articulador de mudanças, considerando que ela "pode ser [...] a principal instituição da construção do novo" (BUARQUE, 1994, p. 51), no que tange à efetiva execução da Lei n ${ }^{0}$ 10.639/2003. Que a extensão universitária e a formação continuada possam sempre promover medidas afirmativas, de caráter inclusivo, da preservação e evidência da cultura africana e afro-brasileira, como forma de combate ao racismo estrutural existente em nosso país. Que mantenhamos o sonho de transformar a escola e o fazer pedagógico, em prol do valor do reconhecimento da diversidade étnico-racial, na construção de um currículo pluriétnico e de uma educação antirracista e inclusiva.

\section{Referências:}

ALMEIDA, Silvio Luiz de. Racismo Estrutural. São Paulo: Sueli Carneiro: Pólen, 2019.

ANDRADE, Alcilene Costa; FREITAS, Lígia Luís de; BARBOSA, Maria José Candido. Políticas educacionais de formação docente após a implementação da Lei 10.639/03 - a experiência de João Pessoa. 25․ Simpósio Brasileiro de Política e Administração da Educação e $2^{o}$. Congresso Ibero-Americano de Política e Administração da Educação. Políticas Públicas e Gestão da Educação: construção histórica, debates contemporâneos e novas perspectivas. ANPAE. 23 a 30 Abril de 2011 , São Paulo. Disponível em: $<$ https://anpae.org.br/simposio2011/cdrom2011/trabalhosCompletoso 1.htm >. Acesso em: 01.jun.2020.

BITTENCOURT JÚNIOR, Iosvaldyr Carvalho; SILVA, Paulo Sérgio da. Por um novo fazer pedagógico em sala de aula: os contornos pedagógicos de uma perspectiva de Educação Quilombola. In: SOUZA, Edileuza Penha de; NUNES, Georgina Helena Lima; MELO, Willivane Ferreira de. Memória, Territorialidade e experiências de Educação Escolar quilombola no Brasil. Pelotas: Ed. UFPel, 2016. p. 223- 233. 
Revista Educação e Políticas em Debate - v. 9, n. 3, p. 692 - 707, set/dez. 2020 - ISSN 2238-8346

BRASIL. Ministério da Educação. Documento Final da Conferência Nacional de Educação (Conae). Brasília: 2014. Disponível em:

<http://confinteabrasilmais6.mec.gov.br/images/documentos/documento final CONAE _2014.pdf>. Acesso em: jan. 2015.

BRASIL. Lei 10.639, de 09 de janeiro de 2003. Altera a Lei $n^{\circ}$ 9.394, de 20 de dezembro de 1996, que estabelece as diretrizes e bases da educação nacional, para incluir no currículo oficial da Rede de Ensino a obrigatoriedade da temática "História e Cultura Afro-Brasileira", e dá outras providências. Diário Oficial [da] República Federativa do Brasil. Poder Executivo, Brasília, DF, 10 jan. 2003. Disponível em:

< http://www.planalto.gov.br/ccivil 03/leis/2003/110.639.htm>. Acesso em: 07 jun. 2020.

BRASIL. Ministério da Educação. Conselho Nacional de Educação. Resolução nº 1, de 17 de junho de 2004. Institui Diretrizes Curriculares Nacionais para a Educação das Relações Étnico Raciais e para o Ensino de História e Cultura Afro-Brasileira e Africana. Disponível em: $<$ http://portal.mec.gov.br/cne/arquivos/pdf/res012004.pdf $>$. Acesso em: 07 jun. 2020.

BRASIL. Ministério da Educação. Diretrizes Curriculares Nacionais para a Educação das Relações Étnico-Raciais e para o Ensino de História e Cultura Afro-Brasileira e Africana. Secretaria Especial de Políticas de Promoção da Igualdade Racial. Instituto Nacional de Pesquisas Educacionais Anísio Teixeira. Brasília: 2005.

BRASIL. Secretaria de Educação Fundamental. Parâmetros curriculares nacionais: terceiro e quarto ciclos do ensino fundamental: introdução aos parâmetros curriculares nacionais / Secretaria de Educação Fundamental. - Brasília: MEC/SEF, 1998.

BRASIL. Ministério da Educação e Cultura. Lei nº 9394 de 20 de dezembro de 1996. Estabelece as diretrizes e bases da educação nacional. Disponível em: <http://www.planalto.gov.br/ccivil_03/leis/19394.htm>. Acesso em: 07 jun. 2020.

BUARQUE, Cristovam. A Aventura da Universidade. São Paulo: Editora da Universidade Estadual Paulista: Paz e Terra, 1994.

CANEN, Ana. Universos culturais e representações docentes: subsídios para a formação de professores para a diversidade cultural. Educação e Sociedade, nº 77, p. 207-227, 2001. DOI: https://doi.org/10.1590/S0101-73302001000400010.

CUSTÓDIO, Simone M.; MONNI, Suzana dos S. Cachoeirinha - tutoria presencial e à distância: duas caminhadas em um único objetivo. In: SABALLA, Viviane A.; BITTENCOURT JÚNIOR, Iosvaldyr C. Procedimentos Didático-Pedagógicos aplicáveis em História e cultura Afro-Brasileira. Porto Alegre: Editora da UFRGS, 2012. p. 140-150.

D’ADESKY, Jacques. Racismo e Anti-Racismo no Brasil. Rio de Janeiro: Pallas, 2009.

DOURADO, Luiz Fernandes. Formação de Profissionais do Magistério da Educação Básica: novas diretrizes e perspectivas. Revista Comunicação $\Xi$ Educação. Revista do Departamento de Comunicação e Artes da ECA/USP, São Paulo, número 1, Ano XXI, p. 27-39, jan.-jun. 2016. Disponível em <http://www.revistas.usp.br/comueduc/article/view/110712> Acesso em 14. mai. 2017. DOI: https://doi.org/10.11606/issn.2316-9125.v21i1p27-39. 
Revista Educação e Políticas em Debate - v. 9, n. 3, p. 692 - 707, set/dez. 2020 - ISSN 2238-8346

DOURADO, Luiz Fernandes. Diretrizes Curriculares Nacionais para a Formação Inicial e Continuada dos Profissionais do Magistério da Educação Básica: concepções e desafios.

Educação e Sociedade, Campinas, v. 36, nº 131, p. 299-324, abr.-jun. 2015. DOI:

https://doi.org/10.1590/es0101-73302015151909.

ESTRELA, Maria Tereza. A formação contínua, teoria e prática. In: FERREIRA, Naura Syria Carrapeto. (Org.). Formação Continuada e Gestão da Educação. São Paulo: Cortez, 2006. p. 43-64.

FANON, Frantz. Peles negras, máscaras brancas. Rio de Janeiro: Ed. Fator, 1983.

FARIA FILHO, Luciano; BAHIENSE, Priscilla N. Pensar a Educação, pensar o Brasil (1822-2022): ensino, pesquisa, extensão. Extensio: Revista Eletrônica de ExtensãoUniversidade Federal de Santa Catarina, Florianópolis, v. 1, p.15-25, 2004.

GUIMARÃES, Antônio Sérgio Alfredo. Racismo e Antirracismo no Brasil. São Paulo: Edição 34, 2009.

GURGEL, R. M. Extensão Universitária: comunicação ou domesticação. São Paulo: Cortez, 1986.

HASENBALG, Carlos; SILVA, Nelson do Valle; LIMA, Márcia. Cor e Estratificação Social. Rio de Janeiro: Contracapa Livraria, 1999.

HASENBALG, Carlos; SILVA, Nelson do Valle; LIMA, Márcia. Discursos sobre a raça: pequena crônica de 1988. In: Cadernos Cândido Mendes. Estudos Afro-Asiáticos, no. 20, p. 187-196, 1991.

LOPES, Véra Neusa. Construindo uma escola de qualidade: considerações sobre Educação Étnico-Racial e Ensino de História e Cultura Afro-brasileira e Africanas. In: SANTOS, Antônio José dos; CAMISOLÃO, Rita de Cássia; LOPES, Véra Neusa et al (Org.). Tramando Falas e Olhares, compartilhando saberes: contribuições para uma educação anti-racista no cotidiano escolar. Porto Alegre: Editora da UFRGS, 2008. p. 143-158.

MACEDO, José R. Os Educadores em face da Legislação antirracista: o desafio necessário. In: SABALLA, Viviane A.; BITTENCOURT JÚNIOR, Iosvaldyr C. Procedimentos Didático-Pedagógicos aplicáveis em História e cultura Afro-Brasileira. Porto Alegre: Editora da UFRGS, 2012. p. 29-43.

MUNANGA, Kabengele. (Org.). Rediscutindo a mestiçagem no Brasil. Petrópolis: Vozes, 1999.

NAVES, Emilse Terezinha. Fazer-saber: reflexões sobre a função acadêmica da extensão universitária. Revista Em Extensão da Universidade Federal de Uberlândia, Uberlândia, V. 14, n. 1, p. 9-29, 2008. DOI: https://doi.org/10.14393/ree-v14n12015_art01.

NEZ, Egeslaine de. Da Leitura de aula ao Cinema Universitário: um relato da interface ensino, pesquisa e extensão. Revista Expressa Extensão, Pelotas, V. 19, n. 1, p. 109-123, 2014.

OLIVEIRA, Luiz Fernandes de. Opção decolonial e antirracismo na educação em tempos neofascistas. Revista da $A B P N$, v. 12, no. 32, p. 11-29, março-maio 2020. DOI:

https://doi.org/10.31418/2177-2770.2020.v12.n.32.p11-29.

OLIVEIRA, Luiz Fernandes de. História da África e dos africanos na escola. Rio de Janeiro: Ed. Imperial Novo Milênio/FAPERJ, 2012. 
Revista Educação e Políticas em Debate - v. 9, n. 3, p. 692 - 707, set/dez. 2020 - ISSN 2238-8346

OLIVEIRA, Luiz Fernandes de. A construção dos fundamentos teóricos de uma nova política pública de promoção da igualdade racial na Educação brasileira. In: NASCIMENTO, Alexandre do et all (Org). Histórias, Cultura e Territórios Negros na Educação: reflexões docentes para uma reeducação das relações étnico-raciais. Rio de Janeiro: E-papers, 2008, p. 7-45.

PERONI, Vera. Política Educacional e papel do Estado no Brasil dos anos 1990. São Paulo: Xamã, 2003.

PIZZI, Jovino; BASTO; Matheus B. Apresentação. Revista Expressa Extensão, v. 2 1, n. 2, p. 4, Jul.-Dez 2016. Disponível em:

https://periodicos.ufpel.edu.br/ojs2/index.php/expressaextensao/index. Acesso em 18. Mai. 2017.

RIBEIRO, Djamila. Lugar de Fala. São Paulo: Sueli Carneiro: Pólen, 2019.

SABALLA, Viviane A.; BITTENCOURT JÚNIOR, Iosvaldyr C. Procedimentos DidáticoPedagógicos aplicáveis em História e cultura Afro-Brasileira. Porto Alegre: Editora da UFRGS, 2012.

SABALLA, Viviane A.; BITTENCOURT JÚNIOR, Iosvaldyr C. Patrimônio e Cultura: compromisso social da universidade na preservação da memória. Diálogo, Canoas, n. 8, p. 173-186, jan.-jun. 2006.

SILVA, Paulo Sérgio da. A Articulação em Rede: o papel fundamental das Secretarias Municipais na implementação didático-pedagógica da temática afro-brasileira nas escolas. In: SABALLA, Viviane A.; BITTENCOURT JÚNIOR, Iosvaldyr C. Procedimentos Didático-Pedagógicos aplicáveis em História e cultura Afro-Brasileira. Porto Alegre: Editora da UFRGS, 2012. p. 123-126.

SILVA, Petronilha Beatriz Gonçalves e. Prefácio. In: SABALLA, Viviane A.; BITTENCOURT JÚNIOR. Iosvaldyr C. Procedimentos Didático-Pedagógicos aplicáveis em História e cultura Afro-Brasileira. Porto Alegre: Editora da UFRGS, 2012. p. 9-12.

SILVA, Petronilha Beatriz Gonçalves e. Africanidades Brasileiras: esclarecendo significados e definindo Procedimentos Pedagógicos. Revista do Professor, Porto Alegre, v. 19, no. 73, p. 26-30, jan- mar. 2003.

SOUZA, Carlos Alberto de. Et al. Tutoria na Educação à Distância. Gestão de Sistemas de Educação à Distância. Educação Universitária, 2004. Disponível em

<http://www.abed.org.br/congresso2004/por/htm/088-TC-C2.htm>. Acesso em: 17. mai. 2017.

SOUZA, Edílson Fernandes de; REIS, Maria da Conceição dos; MENEZES, Vilde Gomes de. Política de educação das relações etnicorraciais: especificidades e caminhos da legislação brasileira. Revista Reflexão e Ação, Santa Cruz do Sul, v.21, n. esp., p.08-30, jan./jun.2013.

SOUZA, Leira S. T. de; FERNADES, Evandro. Novo Hamburgo - Reflexões sobre o Programa de Educação Anti-Racista no Cotidiano Escolar e Acadêmico da Pró-Reitoria de Extensão da Universidade Federal do Rio Grande do Sul. In: SABALLA, Viviane A.; BITTENCOURT JÚNIOR, Iosvaldyr C. Procedimentos Didático-Pedagógicos aplicáveis em História e cultura Afro-Brasileira. Porto Alegre, Editora da UFRGS, 2012. p.127-139.

TARDIF, Maurice. Saberes Docentes e Formação Profissional. Rio De Janeiro: Vozes, 2014. 